\title{
Celso Furtado: \\ criatividade e dependência na periferia
}

"Poucas pessoas são feitas para a independência, isto é privilégio daqueles que têm personalidade forte.”

(Friedrich Nietzsche)

\begin{abstract}
D ESEnHAR um livro de Furtado é um grande desafio, ainda mais o livro em questão. Dada a riqueza e a profundidade das discussões que propõe, certamente cada leitor faria um recorte diferente com toda a propriedade. Furtado é um autor que, cada vez que relemos, percebemos elementos que não tínhamos em conta antes.
\end{abstract}

Criatividade e dependência da civilização industrial, como outros livros de Furtado, é uma obra nascida da alma do autor, escrita com paixão e profundidade, surgida da necessidade de refletir e buscar respostas para o problema do desenvolvimento em economias periféricas. Trata-se de um trabalho reflexivo que envolve toda a complexidade e a contradição presentes no tema, passando da razão instrumental civilizatória de Kant à angústia de Nietzsche ante um mundo que "subordina os fins aos meios" (p.202-3).

Furtado se pergunta - talvez vagando com um "andar sozinho, de vagabundear como um lobo solitário..." (Furtado, 1992, p.22), como um Jean-Jacques Rousseau, refletindo nas ruas de Paris o que impedia as economias periféricas latino-americanas de se desenvolverem plenamente. Como aponta no prefácio, "O fio condutor é a perplexidade do autor em face do mundo de sombras que contorna as minúsculas clareiras em que se arrincoam as ditas ciências"; e o resultado são páginas escritas a partir dos diálogos que "mantemos incessantemente com as sombras que entrevemos" (p.33).

Esta é uma nova edição do livro escrito em 1978. Apesar do seu óbvio valor histórico, o que o torna fundamental é a atualidade das discussões. É uma obra essencial de Celso Furtado, republicada exatamente em um momento em que a questão do desenvolvimento volta ao debate acadêmico e político diante da crise das políticas liberalizantes levadas a cabo ao longo dos anos 1990, crise essa concretamente sentida nos mercados financeiros norte-americanos e mundiais. Sua atualidade também se manifesta pelo fracasso das mesmas políticas em promover o desenvolvimento da América Latina.

Torna-se um livro ainda mais fundamental diante do aparente sucesso da "via chinesa", que constituiu uma estratégia de construção do que Furtado chama "civilização industrial" como nação soberana, possibilidade que já apontou no livro. Discute a já então conhecida estratégia japonesa de desenvolvimento que elevou o país ao rol dos desenvolvidos e, como sabemos, constituiu o pólo hegemônico oriental do capitalismo mundial, lugar hoje disputado pela China. Assim, tem muito a contribuir com a discussão atual. 
Em seus artigos dos anos 1950-1960 sobre o tema do desenvolvimento, ainda muito envolvido no pensamento cepalino, Furtado estava preocupado em justificar economicamente a necessidade da industrialização da periferia como uma forma de ingresso no mundo desenvolvido. Apontava ser essa a fórmula para a criação na periferia de um fluxo de acumulação dinâmico endógeno produção-renda-consumo -, o modo de superar a lógica primário-exportadora que caracterizava as economias dos países latino-americanos, talvez capaz de torná-las desenvolvidas.

É interessante como, já a partir de meados dos anos 1960, após a enorme onda industrializante na periferia, Furtado passa a se questionar sobre a estratégia empreendida. ${ }^{2}$ Foi um sucesso em industrializar a periferia, mas não havia eliminado as relações de dependência; ao contrário, elevou-as a um novo patamar. A nova dependência configuravase como tecnológica e, como destacava, estava ligada a componentes culturais. A estrutura industrial criada por substituição de importações, com tecnologia importada, baseava-se na produção de bens de consumo de elite, implicando uma forte concentração de renda. A industrialização da periferia teria entregado a dinâmica industrial a grupos transnacionais. Simplesmente transplantou estruturas produtivas e tecnologias modernas criadas no centro para a periferia sem gerar mecanismos de apropriação sobre essa tecnologia, sem recriar internamente a lógica central do que denomina, no livro em tela, "civilização industrial", fundada em uma relação amalgamada entre cultura, criatividade e tecnologia.

Talvez tenha sido a partir desse ponto que nasceram em Furtado as indagações aprofundadas de forma madura nesse livro escrito em 1978. Ao que parece, sua preocupação teve origem nos chamados "debates de Santiago" (cf. Furtado, 1992), onde se reuniam exilados da ditadura para discutir os problemas que impediam o desenvolvimento. E, como o próprio Furtado aponta, foram questões que o atormentaram em suas andanças na Europa e nos Estados Unidos. Havia ocorrido a industrialização, mas essa se constituiu em um acesso indireto à "civilização industrial”, vinculada a relações internacionais e ao movimento do capital mundial, com características específicas, que mantém a economia inserida em uma lógica dependente. O próprio esforço de industrialização teria sido reflexo da expansão do capitalismo no centro do sistema para a periferia, e não a constituição soberana da "civilização industrial". Essa forma de inserção se materializa na lógica industrializante fundada no processo de transposição de grupos transnacionais a partir do centro; portanto, subordinada ao grande capital.

É por isso que a periferia não consegue reconstituir a "civilização industrial" e mantém-se como um apêndice dela. As estratégias japonesa e soviética foram diferentes. Segundo o autor, buscaram uma via de desenvolvimento em razão de um projeto de afirmação nacional e, por isso, conseguiram assimilar de forma integrada e ao mesmo tempo soberana, pela força do Estado organizador, as mesmas transformações sociais que constituíram as bases formadoras da estrutura produtiva e social européia. A periferia latino-americana não traça o mesmo caminho. Sua estratégia modifica a relação centro-periferia primárioexportadora, mas não consegue superar a dependência. 
Furtado então se pergunta: em que se constitui a "civilização industrial" que a periferia latino-americana penetra de forma indireta e subordinada? Claro, trata-se da base constitutiva da sociedade burguesa capitalista, mas não basta colocar a questão dessa forma, é preciso aprofundá-la. Para Furtado, a "civilização industrial" é o resultado de uma transformação social que subordina a força física e a capacidade intelectual, criativa, à lógica da acumulação de riqueza. Está relacionada a uma estrutura de poder ligada à ideologia da acumulação, à racionalidade instrumental para a organização da produção que condiciona o desenvolvimento das forças produtivas e a própria sociedade. Assim, acumulação, criatividade, técnica, cultura e padrão de consumo constituem-se em um mecanismo lógico fundador da organização social criada pela civilização burguesa, pela Revolução Industrial. No desenvolvimento real, o fluxo dinâmico ultrapassa em muito seu aspecto simplesmente econômico presente em seus primeiros estudos.

Existe, portanto, nas sociedades surgidas do capitalismo industrial, uma relação estrutural entre o grau de acumulação alcançado, o grau de sofisticação das técnicas produtivas e o nível de diversificação dos padrões de consumo dos indivíduos e da coletividade. (p.64)

A constituição material concreta dessa civilização industrial está estruturada na relação entre a grande empresa, a organização social e o Estado Nacional. A grande empresa concentra o poder econômico e o controle sobre os mercados. É ela a responsável pela hierarquização das relações sociais que condicionam o comportamento humano para a produção; disciplina, junto com o Estado, a força de trabalho; toma a iniciativa da acumulação, orienta a criatividade para a modernização constante, transformando-a em tecnologia; e controla a comunidade com fins da acumulação. Mas, aponta Furtado, se a sociedade fosse constituída apenas pela existência da grande empresa, o resultado seria a concentração de riqueza e poder e não se criaria o padrão de consumo necessário à própria acumulação. Assim, de outro lado estão as instituições sociais constituídas pelos trabalhadores organizados em sindicatos que lutam pela distribuição social dos frutos do crescimento da produtividade que a acumulação engendra. Portanto, avanço tecnológico e padrão de consumo andam juntos. Por fim, o Estado surge como elemento central. Constituído historicamente, é o responsável pela articulação desses dois sistemas de forças antagônicos que garantem a própria sustentação histórica da lógica capitalista (p.53).

Essas são as bases da idéia de desenvolvimento em que se funda a civilização industrial. Desenvolvimento visto como capacidade de criar soluções originais para problemas específicos que resultam em mudanças sociais e extração de excedente. É “um processo histórico cuja dinâmica se apóia na inovação técnica (fundada na experiência empírica ou em conhecimentos científicos) posto ao serviço de um sistema de dominação social", capaz, pela acumulação que daí resulta, de transformar as estruturas sociais e as formas comportamento (p.83). Portanto, é o resultado da subordinação da criatividade - algo que não reproduz o existente, mas fundamenta-se em ampliar o campo do possível - a uma racionalidade instrumental que amplia a acumulação.

Nesse sentido, desenvolvimento é o acesso à civilização industrial. Mas como 
os países de industrialização retardatária poderiam construir essa ponte de acesso? Para Furtado, não existe uma tipologia ou uma fórmula preconcebida, um modelo. Tomando os exemplos de acesso soberano do Japão e da ex-União Soviética, o autor encontra alguns pontos em comum importantes: a forte participação do Estado Nacional dominado por uma ideologia modernizante, atuando com os mesmos critérios de racionalidade e controle social presente na estratégia das grandes corporações, com toda a racionalidade instrumental que as caracteriza. Assim, esses países encontraram o caminho mais curto para transplantar a civilização material já existente na Europa, construindo um acesso direto à civilização industrial, não independente, mas soberano, na medida em que internalizaram sua lógica por completo: acumulação, criatividade, tecnologia, cultura e padrão de consumo. Criaram estruturas industriais próprias a partir do controle do Estado.

Essa não foi a estratégia e a história das periferias em situação de dependência que, como afirma Furtado, realizaram o "acesso indireto à civilização industrial", como uma decorrência das próprias relações históricas de dependência centroperiferia. Esses países realizaram sua modernização pela transposição da cultura e da criatividade que se constituem em tecnologia, originárias do centro. A industrialização tardia resultou na produção local controlada por filiais e subsidiárias de grandes grupos transnacionais que têm sua base de decisão e produção de tecnologia no centro, e que, na verdade, queriam, além dos mercados periféricos, se livrar do controle social ao qual estavam submetidos no centro. Assim, o capitalismo periférico já nasce formado por oligopólios ou monopólios controlados de fora. Funda-se, portanto, em padrões culturais e de consumo que não se constroem na periferia e aos quais apenas uma elite tem acesso. Por isso, convivem formas modernas transplantadas do centro com atrasadas constitutivas da periferia; uma elite de padrões europeus convive com uma população pobre em setores tradicionais. Assim, a relação empresas, organização social e Estado já nasce truncada.

Dessa forma, pode-se facilmente notar que esse processo é totalmente diferente do que Furtado denomina civilização industrial constituída na Europa. “As transformações estruturais são um esforço de adaptação em face do transplante maciço de técnicas geradas em sociedades que se encontram em fase bem mais avançada de acumulação" (p.109). E por isso convivem padrões sociais das sociedades avançadas com a pobreza periférica. Na periferia, a idéia de desenvolvimento fundou-se em uma forma específica de aliança com a civilização industrial, elevando a dependência. Esse processo foi, para Furtado, o resultado de um pacto de interesses (interno e externo) fundado numa idéia de progresso que cimenta uma "superideologia" em defesa do desenvolvimento pela simples atração de Investimento Direto Estrangeiro, de empresas transacionais com tecnologias prontas. Essa ideologia não leva em conta que desenvolvimento é o resultado de um processo cultural abrangente. Tem por base a idéia de que a transferência pura e simples de tecnologia recupera o tempo perdido.

A dependência deve ser percebida inicialmente como um conjunto de traços estruturais que emergem da história: a forma de inserção no sistema de divi- 


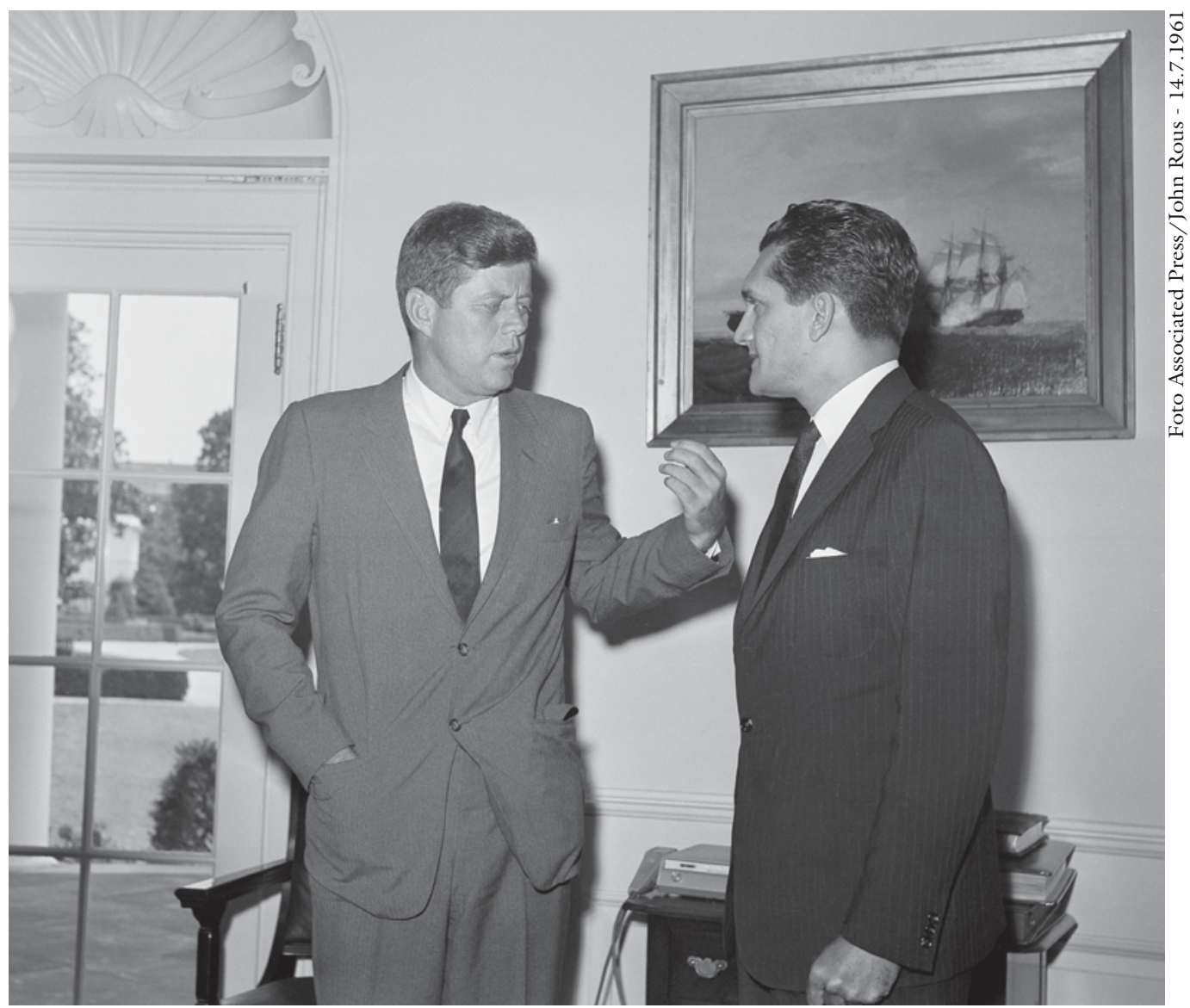

O presidente dos Estados Unidos, John F. Kennedy (1917-1963), e Celso Furtado (1920-2004), então diretor da Sudene (Superintendência de Desenvolvimento do Nordeste), durante reunião realizada em 14 de julho de 1961, na Casa Branca, Washington D.C. (EUA).

são internacional do trabalho gerando atraso relativo no desenvolvimento das forças produtivas; a industrialização supeditada pela modernização reforçando as tendências à concentração de renda; a necessidade de importar certas técnicas facilitando o controle das atividades econômicas pelas empresas transnacionais. (p.146)

Essa forma de inserção da periferia só poderia resultar na ampliação da dependência cultural, da criatividade dada por outros, transpondo para a periferia tecnologia e produtividade do centro. Ainda mais, aponta Furtado, tem sua lógica totalmente fundada em capitais transnacionais que detêm, pela natureza do processo antes exposto, o controle instrumental sobre a criatividade e a cultura em escala global. A industrialização sob essa estrutura só poderia ter conduzido à periferia a formas modernas de servidão, como aponta o autor, fornecendo com sua mão-de-obra barata, avaliada na periferia, produtos sofisticados ao centro, com valor social definido por padrões dos países desenvolvidos.

E como superar essa situação de dependência que se emaranha na cultura, mas que está concretamente dada pela estrutura? Essa é a questão central posta por Furtado, extremamente atual. Seria a solução elevar a subordinação e aprofundar o mecanismo como, aliás, proposto 
por um dos membros presentes nas discussões do grupo de Santiago, e que, ao tornar-se presidente do Brasil nos anos 1990, aprofundou as relações de dependência? Mas, pergunta-se Furtado, seria solução isolar-se? Sua resposta é direta: não existe essa possibilidade. Tampouco seria a subordinação completa (finamente denominada "associada"). A solução para ele é "modificar as relações de força que são substrato da ordem econômica internacional. A luta contra a dependência passa [...] por um esforço para modificar a conformação global do sistema" (p.149), o que seria possível dado o lugar importante que a periferia ocupa no sistema.

A estratégia passa pelo controle sobre recursos de

poder em que se assenta a chamada ordem econômica internacional: a) o controle da tecnologia; b) o controle das finanças; c) o controle dos mercados; d) o controle do acesso às fontes de recursos não renováveis; e e) o controle do acesso à mão-de-obra barata. [...] A luta contra a dependência não é outra coisa senão um esforço dos países periféricos para modificar essa estrutura. $(\text { p.151 })^{3}$

Pode-se dizer que o controle da tecnologia está no centro da questão, dado que "é o recurso mais nobre" e no qual se fundamenta a dependência; é a "trava mestra da estrutura de poder internacional". Mas controlar os outros elementos favorece essa empreitada. A saída é reunir "recursos de poder para neutralizar ainda que parcialmente o peso da dependência tecnológica - eis a essência do esforço que realizam os países periféricos para avançar pela via do desenvolvimento" (p.160). Resgatar a criatividade é o elemento central. "A luta contra a dependência não é senão um aspecto do processo de desenvolvimento, e este não existe sem a liberação da capacidade criadora de um povo." Como a tecnologia constitui a expressão final da criatividade humana, sua libertação constituiria o caminho. Mas como confrontar a forma como essa criatividade é na civilização industrial apropriada e monopolizada pela grande empresa transnacional? Como libertar-se desse fato? Essas não são questões resolvidas por Furtado. Ele crê que seja possível diminuir a dependência "mediante a utilização de combinações adequadas de outros recursos, ou da massa crítica". Talvez a resposta que Furtado nos daria seja: precisamos descobrir pela criatividade.

O mais interessante é que Furtado termina o livro com uma última reflexão fundamental evocando Kant e Nietzsche. Pergunta-se: é isso mesmo? A instalação da civilização industrial é mesmo um fim? Subordinar toda a sociedade a essa lógica não a estaria levando a um despenhadeiro que suprime a própria criatividade humana já subordinada à razão instrumental, ou o homem, ao processo de acumulação de capital? Não se estaria conduzindo à "mediocrização da sabedoria e ao empobrecimento da vida"? "As forças que em nossa civilização engendra a difusão da racionalidade" não estariam conduzindo "concomitantemente à destruição da criatividade humana"?

Apesar de colocar essas questões diretamente como riscos em operação na civilização industrial, talvez sua resposta seja negativa a todas elas. Acompanhando Nietzsche, aponta a condição superior do homem - um criador por natureza - como a chave para a capacidade de libertar-se daquilo que constrange, 


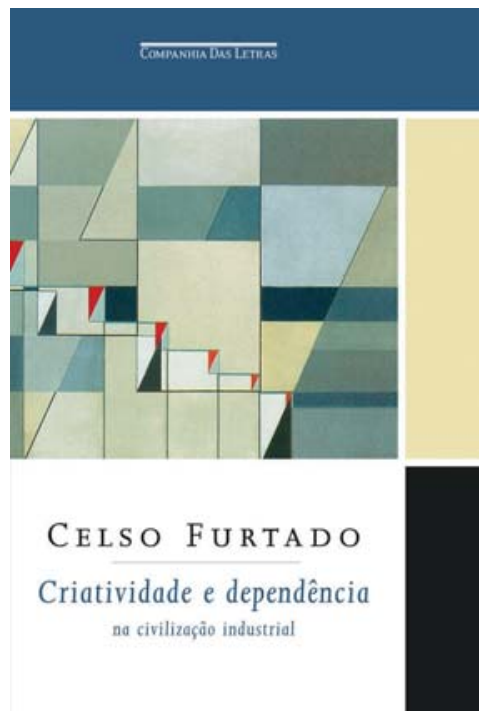

FURTADO, Celso. Criatividade e dependência da civilização industrial. São Paulo:

Cia. das Letras, 2008. 224p.

de romper com o estabelecido por meio da criatividade "que outra coisa não é senão o verdadeiro humano" (p.206). "A liberdade humana projeta-se $[\ldots]$ num plano epistemológico que escapa às 'leis naturais' explicativas de uma realidade a priori reduzida..." O homem tem a faculdade de transformar-se, afirma.

$\mathrm{O}$ fato de a criatividade gravitar em torno da acumulação seria uma característica específica dessa civilização industrial, do capitalismo que transforma tudo em mercadoria e a criatividade em meio de acumulação. Essa não é uma característica natural imutável. A própria inovação sempre teve como seu fundamento original ampliar o horizonte e as possibilidades humanas, afirma $\mathrm{O}$ autor. De forma contraditória, o sistema da civilização industrial se funda sobre a criatividade ao mesmo tempo que a restringe à criatividade utilitarista, aprisionando a liberdade humana "num la- birinto borgiano". O homem é afastado de sua criação, o que constitui "a manifestação mais dramática de sua alienação" (p.208). Perdeu, assim, de fato, o controle sobre sua criação. Está preso nas engrenagens por ele mesmo criadas. "É livre para se ver nas engrenagens, mas não o suficiente para escapar delas." Diga-se de passagem que essas conjecturas referem-se tanto ao centro como às condições criadas na periferia.

A saída para Furtado está na organização social, também um resultado da criatividade humana. Ainda em plena ditadura militar e no exílio, Furtado acreditava e defendia a ação política, como forma de modificação do homem, do mundo, das relações de dependência, mas uma ação pelo seu veículo fundamental: o Estado. Para ele, a raiz dos problemas está na falta de coordenação que a transnacionalização, ou globalização, do capitalismo cria no sistema, dificultando a ação criativa em busca de saídas, subordinando tudo à lógica da acumulação, no centro e na periferia. $\mathrm{O}$ homem depende, portanto, da única coisa que lhe resta e que se manifesta como liberdade: a política, o "único espaço em que a civilização industrial floresceu autêntica atividade criadora". A única forma é conquistar o controle político sobre as atividades econômicas, e isso passa pelo Estado.

Segundo Furtado, é a própria capacidade de percepção do homem, essa situação de estranhamento em que se encontra diante de sua criação, que lhe permite a capacidade de reação. Sua história não acabou. Talvez pudéssemos tomar a idéia de Nietzsche: o homem é predestinado a ser livre. Sua criatividade não segue um determinismo causal; ao contrário, é capaz de eliminar todas as formas de determinismo. 
Tudo se passa como se o homem houvesse desesperado de "aperfeiçoar" as engrenagens que criou, de criticar a razão a partir da própria razão, de defender-se da técnica com mais técnica. E para mudar o rumo, volta às próprias origens, retoma contato com suas dimensões secretas, assume a plena lucidez. E toma pé no fundamental, na essência humana, que é a ânsia de ser livre. (p.229)

Notas

1 Cf. Furtado (2000), que agrega ensaios escritos entre 1952 e 1966.

2 Cf. Furtado (1978), que agrega ensaios escritos entre 1964 e 1968; e Furtado (1996), com ensaios escritos entre 1972 e 1974 nos Estados Unidos.

3 Talvez, tudo o que a China esteja buscando fazer.

Referências bibliográficas

FURTADO, C. A hegemonia dos Estados Unidos e o subdesenvolvimento da América Latina. Rio de Janeiro: Civilização Brasileira, 1978.

. Os ares do mundo. São Paulo: Paz e Terra, 1992.

. O mito do desenvolvimento econômico. São Paulo: Paz e Terra, 1996.

Teoria política do desenvolvimento econômico. São Paulo: Paz e Terra, 2000.

Rubens R. Sawaya é doutor em Ciência Política, mestre em Economia Política, professor do Departamento de Economia da PUC-SP e autor do livro Subordinação consentida: capital multinacional no processo de acumulação da América Latina e Brasil (Annablume, 2006).

@ - rsawaya@uol.com.br 